\title{
Mutation analysis in glutaric aciduria type I
}

\author{
Johannes Zschocke, Elfriede Quak, Per Guldberg, Georg F Hoffmann
}

\begin{abstract}
Glutaric aciduria type 1 (GA1), resulting from the genetic deficiency of glutarylCoA dehydrogenase (GDH), is a relatively common cause of acute metabolic brain damage in infants. Encephalopathic crises may be prevented by carnitine supplementation and diet, but diagnosis can be difficult as some patients do not show the typical excretion of large amounts of glutaric and 3-hydroxyglutaric acids in the urine. We present a rapid and efficient denaturing gradient gel electrophoresis (DGGE) method for the identification of mutations in the glutaryl-CoA dehydrogenase $(G C D H)$ gene that may be used for the molecular diagnosis of GA1 in a routine setting. Using this technique, we identified mutations on both alleles in 48 patients with confirmed GDH deficiency, while no mutations were detected in other patients with clinical suspicion of GA1 but normal enzyme studies. There was a total of 38 different mutations; 27 mutations were found in single patients only, and 21 mutations have not been previously reported. Fourteen mutations involved hypermutable $\mathrm{CpG}$ sites. The commonest GA1 mutation in Europeans is R402W, which accounts for almost $40 \%$ of alleles in patients of German origin. GCDH gene haplotypes were determined through the analysis of polymorphic markers in all families, and three CpG mutations were associated with different haplotypes, possibly reflecting independent recurrence. The high sensitivity of the DGGE method allows the rapid and cost efficient diagnosis of GA1 in instances where enzyme analyses are not available or feasible, despite the marked heterogeneity of the disease.

(f Med Genet 2000;37:177-181)
\end{abstract}

Keywords: glutaric aciduria type I; glutaryl-CoA dehydrogenase; mutation; denaturing gradient gel electrophoresis

Over the last decade, glutaric aciduria type I (GA1, McKusick 231670) has been recognised as a major inherited cause of acute metabolic brain damage in early childhood. ${ }^{1}$ The autosomal recessive disease is caused by a deficiency of the mitochondrial enzyme glutarylCoA dehydrogenase (GDH, EC 1.3.99.7) in the catabolism of lysine, hydroxylysine, and tryptophan. It is characterised by the accumulation of glutaric and 3-hydroxyglutaric acids and secondary carnitine depletion. Affected children are generally well in the first months of life or show only mild neurological symptoms, but usually display increasing macrocephaly. Typically during a non-specific illness or vaccination between 6 and 18 months of age, they suffer a severe encephalopathic crisis that causes necrosis of the striatum in the basal ganglia and results in a severe dystonic dyskinetic movement disorder. Intellectual function is relatively unaffected. The metabolic crisis can usually be prevented by carnitine supplementation and diet, and early presymptomatic diagnosis is therefore essential. As some children show a normal pattern of urinary organic acids, enzymatic or molecular analyses may be necessary in the diagnostic process. $^{2}$

The $G C D H$ gene stretches over $7 \mathrm{~kb}$ on chromosome $19 \mathrm{p} 13.2$ and comprises 11 exons. ${ }^{34}$ The gene product is a polypeptide of 438 amino acids, of which 44 N-terminal residues are removed after mitochondrial import; 63 different disease causing mutations in the gene have been described so far. ${ }^{5}$ Single common mutations are found in genetically homogeneous communities such as the Amish of Pennsylvania, ${ }^{6}$ but GA1 in general is quite heterogeneous; the most frequent mutation in whites, R402W, has been identified on $10-20 \%$ of alleles. ${ }^{5}$ Routine GA1 mutation analysis in a diagnostic setting therefore requires a sensitive and efficient method for the detection of novel DNA alterations. We have devised a denaturing gradient gel electrophoresis (DGGE) system to analyse the whole $G C D H$ gene in genomic DNA. Uniform PCR conditions and a single polyacrylamide gel are used for all exons, and both mutations in a patient can be identified within three days. Presented here are the results of the molecular analysis in 57 subjects with confirmed or suspected GA1.

\section{Subjects and methods}

A total of 57 families was investigated, including most known patients with GA1 in Germany. Most patients in the study had classical GA1 but some displayed atypical clinical or biochemical features, such as consistent isolated urinary excretion of 3-hydroxyglutaric acid, or were referred for exclusion of GA1. GDH deficiency was previously or subsequently proven by enzyme analysis in 46 patients (E Christensen, Copenhagen). Normal GDH activity was found in eight patients, while no enzymatic data were available in three patients. Patients and, where available, both parents were investigated; in one family no patient DNA was available. The families studied were unrelated, but the parents of some patients were related or came from areas with a high degree of consanguinity. The ethnic or national background of each parent over several generations was recorded. The origin of
29 September 1999

Accepted for publication 18

October 1999 
Table 1 PCR primer sequences for mutation analyses in the GCDH gene

\begin{tabular}{|c|c|c|c|c|c|}
\hline & \multirow[b]{2}{*}{ Primer name } & \multirow[b]{2}{*}{ Sequence (5'-3') } & \multicolumn{2}{|l|}{ Sequencing } & \multirow[b]{2}{*}{ DGGE Primer 5' tail } \\
\hline & & & $\begin{array}{l}\text { Primer 5' } \\
\text { tail }\end{array}$ & $\begin{array}{l}\text { Product } \\
\text { size (bp) }\end{array}$ & \\
\hline \multicolumn{6}{|c|}{ A DGGE analysis and sequencing of all exons } \\
\hline \multirow[t]{2}{*}{ Exon 1} & $G C D H-1 \mathrm{~F}$ & TCGTTGCTCCGCTCGCTCTG & P51 & 216 & - \\
\hline & $G C D H-1 \mathrm{R}$ & AGTCCСTAAACCСССAGTTC & M13 & & $65 \mathrm{mer}$ \\
\hline \multirow[t]{2}{*}{ Exon 2} & $G C D H-2 \mathrm{~F}$ & AGTGTGGGGTCGGGAGTGTG & P51 & 260 & $40 \mathrm{mer}$ \\
\hline & $G C D H-2 \mathrm{R}$ & CGGGCAGCTCTCGGATTCTG & P172 & & - \\
\hline \multirow[t]{2}{*}{ Exon 3} & $G C D H-3 \mathrm{~F}$ & GAAGGGAGGGCACAGTGAT & P51 & 280 & $60 \mathrm{mer}$ \\
\hline & $G C D H-3 \mathrm{R}$ & GCGGAGGAGCAGTCTCAG & P172 & & - \\
\hline \multirow[t]{2}{*}{ Exon 4} & $G C D H-4 \mathrm{~F}$ & ATAGCCACCCCACCTCAAG & P51 & 261 & - \\
\hline & $G C D H-4 \mathrm{R}$ & AAGGAGGAAGAGGCTTTCAGA & $\mathrm{P} 172$ & & $40 \mathrm{mer}$ \\
\hline \multirow{2}{*}{ Exon 5} & $G C D H-5 \mathrm{~F}$ & TGTCCTTATTCAGCCCTGTC & M13 & 338 & $40 \mathrm{mer}$ \\
\hline & $G C D H-5 \mathrm{R}$ & GACTGTCTTCCTTCCACCAG & P172 & & - \\
\hline \multirow[t]{2}{*}{ Exon 6} & $G C D H-6 \mathrm{~F}$ & GGCAGCCTTGTGACTTTGTC & P172 & 272 & - \\
\hline & $G C D H-6 \mathrm{R}$ & AGTCGGTGAGGGGTCTGAC & M13 & & $40 \mathrm{mer}$ \\
\hline \multirow[t]{2}{*}{ Exon 7} & $G C D H-7 \mathrm{~F}$ & TGGGCAGGTGGTGAACAG & P172 & 373 & - \\
\hline & $G C D H-7 \mathrm{R}$ & CCGCATCCGCAGGTGAC & P51 & & $40 \mathrm{mer}$ \\
\hline \multirow[t]{2}{*}{ Exon 8} & $G C D H-8 \mathrm{~F}$ & CTTTCCCTGCTTCAGAGTTG & P172 & 264 & $40 \mathrm{mer}$ \\
\hline & $G C D H-8 \mathrm{R}$ & CCACACCCCCAGAGAATC & M13 & & - \\
\hline \multirow[t]{2}{*}{ Exon 9} & $G C D H-9 \mathrm{~F}-\mathrm{a}$ & GACGGGGTGGGAGAGTG & P172 & 359 & I \\
\hline & $G C D H-9 \mathrm{R}-\mathrm{a}$ & AGCCCATCAAGGACAAGAG & P51 & & I \\
\hline \multirow[t]{2}{*}{ Exon 9} & $G C D H-9 \mathrm{~F}-\mathrm{b}$ & GCCTCCCCTCGCTCTTAC & / & & $40 \mathrm{mer}$ \\
\hline & $G C D H-9 \mathrm{R}-\mathrm{b}$ & CTCCAGGAAGACACAAGGTC & l & & - \\
\hline \multirow[t]{3}{*}{ Exon 10} & $G C D H-10 \mathrm{~F}$ & GCCCACTGGTCCCTCATTG & P172 & 378 & $40 \mathrm{mer}$ \\
\hline & $G C D H-10 \mathrm{R}$ & TACCCССТCCCCAGACACT & M13 & & - \\
\hline & $G C D H-\mathrm{c} .1173-\mathrm{R}$ & TACTCGTCAGAAATCCCAGT & / & & 1 \\
\hline \multirow[t]{2}{*}{ Exon 11} & $G C D H-11 \mathrm{~F}$ & AAAACTCCAAACCGACTCTGT & M13 & 418 & l \\
\hline & $G C D H-11 \mathrm{R}-\mathrm{a}$ & GAAGCTGCTATTTCAGGGTAA & P172 & & / \\
\hline \multirow[t]{3}{*}{ Exon 11} & $G C D H-11 \mathrm{~F}$ & AAAACTCCAAACCGACTCTGT & / & & $40 \mathrm{mer}$ \\
\hline & $G C D H-11 \mathrm{R}-\mathrm{b}$ & CGCCACCTCССТTTCTAAG & / & & - \\
\hline & $G C D H-\mathrm{c} .1482-\mathrm{F}$ & TCCCTTCTGAAGTCGATC & I & & I \\
\hline \multicolumn{6}{|c|}{$B$ Primer 5 ' tails for sequencing } \\
\hline M13 & \multicolumn{5}{|c|}{ TATGTAAAACGACGGCCAGT } \\
\hline P172 & \multicolumn{5}{|c|}{ TATTATAGGGCGAATTGGGT } \\
\hline P51 & \multicolumn{5}{|c|}{ TATAAGGGAACAAAAGCTGG } \\
\hline \multicolumn{6}{|c|}{$C$ Primer 5' tails for DGGE } \\
\hline $40 \mathrm{mer}$ & \multicolumn{5}{|c|}{ CGCCCGCCGCGCCCCGCGCCCGTCCCGCCGCCCCCGCCCG } \\
\hline $60 \mathrm{mer}$ & \multirow{2}{*}{\multicolumn{5}{|c|}{ CGCCCGCCGCCCCGCCGCCCGCTCGCCGCCCGCCGCGCCCCTGCCCGCCGCCCCCGCCCG }} \\
\hline $65 \mathrm{mer}$ & & & & & \\
\hline
\end{tabular}

The appropriate universal sequence (B) or GC clamp (C) was attached 5' to the specific primers (A). The ACRS primers GCDHc. 1173-R (together with $10 \mathrm{~F}$, product size $253 \mathrm{bp}$ ) and $G C D H-\mathrm{c} .1482-\mathrm{F}$ (together with $11 \mathrm{R}$-a, product size $141 \mathrm{bp}$ ) were used for the analysis of polymorphisms G391G and c.1482A $>$ G, respectively. Primers for sequencing and DGGE of exons 9 and 11 were at different positions.

families with proven GDH deficiency was as follows: 18 German, nine Turkish (seven living in Germany), four Austrian, six Chilean, and 11 from different European countries and the United States.

Genomic DNA was extracted from peripheral lymphocytes using standard methods. Primer sequences for all exons are given in table 1. For DGGE analysis, a 40-65 bp GC clamp was attached to one of the two exon specific primers. PCR conditions were $95^{\circ} \mathrm{C}$ for three minutes; 35 cycles of $95^{\circ} \mathrm{C}$ for 30 seconds, $60^{\circ} \mathrm{C}$ for 30 seconds, $72^{\circ} \mathrm{C}$ for one minute; followed by $72^{\circ} \mathrm{C}$ for five minutes, $95^{\circ} \mathrm{C}$ for one minute, $65^{\circ} \mathrm{C}$ for 30 minutes, $37^{\circ} \mathrm{C}$ for 30 minutes, $4^{\circ} \mathrm{C}$ hold (Taq polymerase purchased from Life Technologies, Rockville, MD, USA; thermocycler 9700, Perkin Elmer, Norwalk, CT, USA). Amplification of exon 1 for DGGE required the addition of $5 \%$ DMSO. Broad range DGGE was performed on a vertical electrophoresis system (modified Protean II, BioRad, Hercules, CA, USA) using essentially the same procedure and electrophoresis conditions as previously described for the PAH gene. ${ }^{7}$ All exons were run in parallel on the same gel containing a denaturing gradient from $0-80 \%$; electrophoresis time was six hours at $170 \mathrm{~V}$. The relatively short PCR product of exon 8 was loaded 90 minutes after start of the electrophoresis run. The results were visualised by ethidium bromide staining.
Exons displaying variant gel patterns were amplified from genomic DNA with primers containing a universal 20mer tail (table 1), cycle sequenced in both directions with dye labelled universal primers (ThermoSequenase, Amersham Pharmacia, Uppsala, Sweden), and electrophoresed on an ALF express fluorescent sequencer (Amersham Pharmacia, Uppsala, Sweden). Inheritance in the families was confirmed by DGGE or sequencing. Several mutations including R402W were confirmed by appropriate restriction enzyme analyses of the respective exon.

The inheritance of three polymorphic silent mutations in the GCDH gene was investigated with restriction enzyme assays within families. IVS2+63G $>$ C creates an AccI site in intron 2, while c.1173G $>$ T (G391G) in exon 10 and c. $1482 \mathrm{~A}>\mathrm{G}$ in the $3^{\prime}$ untranslated region require amplification with specifically altered PCR primers (table 1), artificially creating $R s a \mathrm{I}$ and $B s i$ EI restriction sites, respectively (ACRS method $^{8}$ ). For the characterisation of alleles using these markers, a small letter (a-h) was assigned to each possible haplotype combination. The numbering of cDNA nucleotides (c.) follows the recommendations of the Nomenclature Working Group ${ }^{9}$ and starts with 1 at the first nucleotide of the initiator codon; values are thus 36 nucleotides smaller than those used in previous publications on GA1 mutations. 

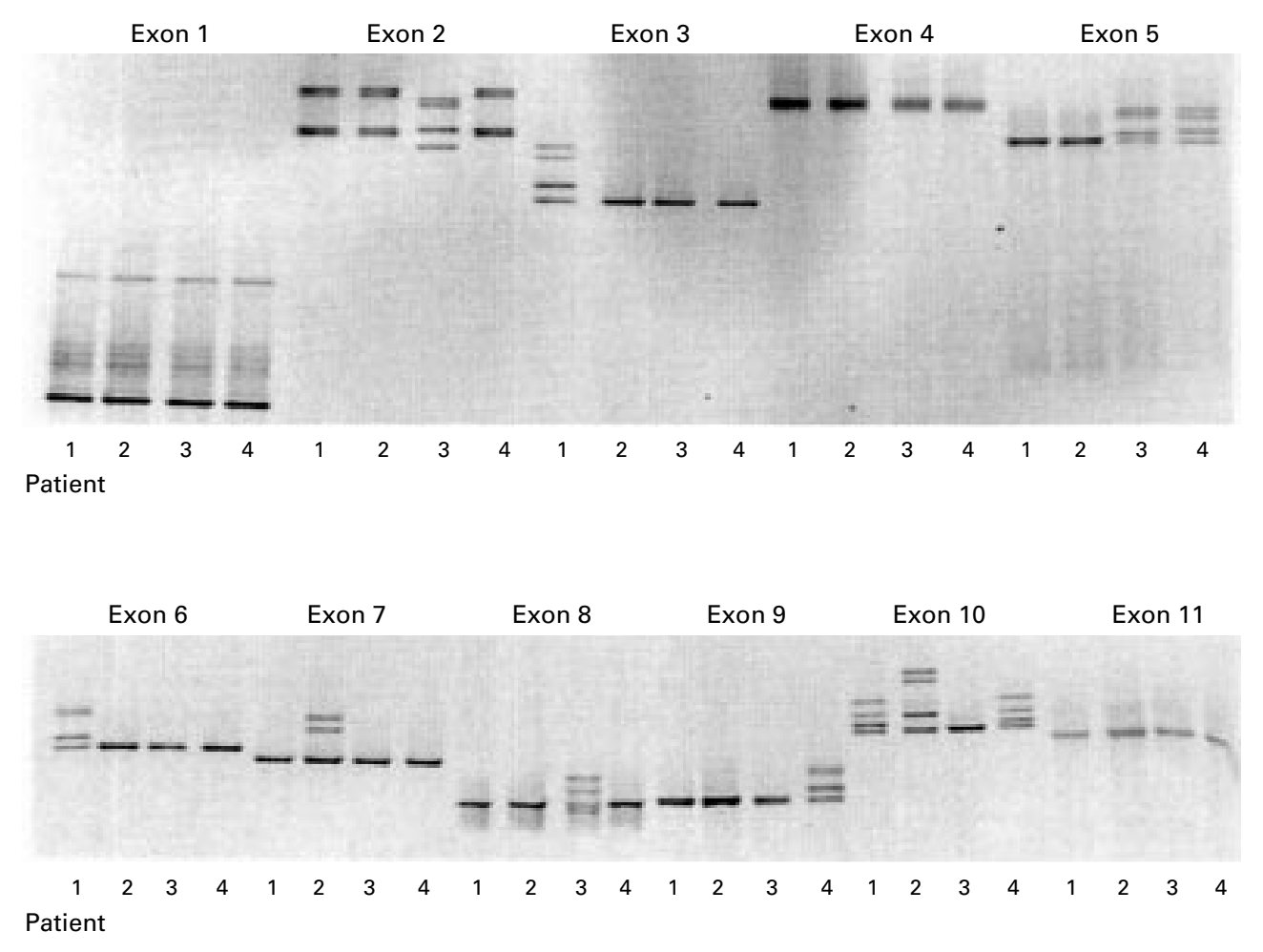

Figure 1 Broad range DGGE in four patients with GA1. Patient 1 is heterozygous for polymorphism IVS2+63G $>C$ in intron 2, mutation R88C in exon 3, mutation A195T in exon 6, and polymorphism G391G in exon 10. Patient 2 is heterozygous for polymorphism IVS $2+63 G>C$, mutation $R 227 P$ in exon 7 , and mutation $R 402 W+$ polymorphism G391G (in cis) in exon 10. Patient 3 is heterozygous for novel silent mutation IVS2+48C>T in intron 2, mutation $R 138 \mathrm{~K}$ in exon 5, and mutation L309W in exon 8. Patient 4 is heterozygous for polymorphism IVS2+63G $>C$, mutation $R 132 Q$ in exon 5, mutation R355H in exon 9, and polymorphism G391G. Polymorphism c. $1482 A>G$ is not contained in the PCR product used for DGGE analysis of exon 11.

\section{Results}

The result of broad range DGGE analysis of all exons of the $G C D H$ gene in four GA1 patients is illustrated in fig 1 . Mutations were found on all 96 GA1 alleles in 48 patient families with unequivocal diagnosis of the disease, including two of the three patients in whom enzyme studies were not performed (table 2). There were 38 different mutations including 20 that have not been previously reported. All but one small deletion were single nucleotide changes; there were three splice site mutations. R402W was confirmed to be the commonest mutation in Europeans, accounting for one quarter of mutant alleles (24/96) in our study. Ten other mutations were also found in more than one family. Fourteen mutations, most of them previously described, were $\mathrm{C}>\mathrm{A}$ or $\mathrm{G}>\mathrm{T}$ alterations at potentially methylated $\mathrm{CpG}$ sites that are known to be hypermutable. ${ }^{10}$ Origin of alleles and haplotype associations are included in table 2. Among both normal and mutant alleles, there were two major ( $\mathrm{a}$ and $\mathrm{h}$ ) and one minor (b) haplotype; the other haplotypes were rare or absent. There was no significant difference in the haplotype distribution between normal and mutant alleles (table 3). With regard to individual mutations, more than half were associated with haplotype a. No mutations were found in the nine patients with atypical clinical or biochemical findings in whom GDH enzyme analysis was normal (eight) or not available (one).
R402W was more common in patients of German origin in whom it had a relative frequency of almost $40 \%$ (14/36 alleles), but it was also identified in patients from various other European countries as well as Chile and the USA. The mutation is usually associated with haplotype $h$ but was found once on a haplotype a background; as a $\mathrm{CpG}$ mutation it may have arisen independently in different founders. Of the four Austrian patients, three were heterozygous and one was homozygous for R88C, a mutation that was not identified in patients from other countries. This clearly reflects a strong regional founder effect. The common "Amish" mutation $\mathrm{A} 421 \mathrm{~V}^{6}$ was detected in patients from Germany, Austria, Croatia, and Italy, indicating a central European origin of the mutation in line with the known historical background of the Amish people. In 22 patients, mutations were found in homoallelic constellations; blood samples from both parents were available in 15 of these families. The father in one Chilean family did not carry the mutation $(\mathrm{Y} 113 \mathrm{H})$ for which his child was homozygous, reflecting either nonpaternity or hemizygosity of $\mathrm{Y} 113 \mathrm{H}$ with a large deletion on the paternal chromosome. ${ }^{11}$ Five of the eight homozygous German patients carried R402W, including one who was heterozygous for $G C D H$ haplotypes. Seven of the nine Turkish patients were homozygous, and the comparatively high rate of consanguinity probably contributes to the relatively 
Table 2 Spectrum of GA1 mutations, haplotype associations, and origin of alleles

\begin{tabular}{|c|c|c|c|c|c|c|c|}
\hline Exon & Mutation & Base change & No & Haplotype & $C p G$ & Novel & Origin \\
\hline & IVS2-2A $>T$ & c. $138-2 \mathrm{~A}>\mathrm{T}$ & 1 & $\mathrm{~b}$ & & $\mathrm{x}$ & Germany \\
\hline \multirow[t]{4}{*}{3} & W50C & c. $150 \mathrm{G}>\mathrm{C}$ & 1 & & & $\mathrm{x}$ & Chile \\
\hline & 219 delC & c. $219 \mathrm{delC}$ & 1 & $\mathrm{a}$ & & $\mathrm{x}$ & Germany \\
\hline & Q76X & c. $226 \mathrm{C}>\mathrm{T}$ & 1 & $\mathrm{~b}$ & & $\mathrm{x}$ & Germany \\
\hline & $\mathrm{R} 88 \mathrm{C}$ & c. $262 \mathrm{C}>\mathrm{T}$ & $5^{\star}$ & a & $\mathrm{x}$ & & Austria \\
\hline \multirow[t]{8}{*}{5} & $\mathrm{Y} 113 \mathrm{H}$ & c. $337 \mathrm{~T}>\mathrm{C}$ & $3 \ddagger$ & $\mathrm{h}$ & & $\mathrm{x}$ & Chile \\
\hline & R128Q & c. $383 \mathrm{G}>\mathrm{A}$ & $3^{\star}$ & $\mathrm{a}$ & $\mathrm{x}$ & $\mathrm{x}$ & Turkey^, Germany \\
\hline & R132Q & c. $395 \mathrm{G}>\mathrm{A}$ & 2 & $a, b$ & $\mathrm{x}$ & $\mathrm{x}$ & Turkey, Germany \\
\hline & V133M & c. $397 \mathrm{G}>\mathrm{A}$ & 1 & $\mathrm{a}$ & & $\mathrm{x}$ & Chile \\
\hline & $\mathrm{R} 138 \mathrm{~K}$ & c. $413 \mathrm{G}>\mathrm{A}$ & 1 & $\mathrm{a}$ & & $\mathrm{x}$ & England \\
\hline & V148I & c. $442 \mathrm{G}>\mathrm{A}$ & 1 & $\mathrm{~h}$ & $\mathrm{x}$ & & England \\
\hline & R161Q & c. $482 \mathrm{G}>\mathrm{A}$ & 1 & $\mathrm{a}$ & $\mathrm{x}$ & & Chile \\
\hline & IVS $5+1 \mathrm{G}>\mathrm{A}$ & c. $515+1 \mathrm{G}>\mathrm{A}$ & $2^{\star}$ & a & & $\mathrm{x}$ & Palestine \\
\hline \multirow[t]{5}{*}{6} & C176R & c. $526 \mathrm{~T}>\mathrm{C}$ & 1 & $\mathrm{~b}$ & & $\mathrm{x}$ & Indonesia \\
\hline & E181Q & c. $541 \mathrm{G}>\mathrm{C}$ & 1 & $\mathrm{~h}$ & & $\mathrm{x}$ & Turkey \\
\hline & $\mathrm{G} 185 \mathrm{~A}$ & c. $554 \mathrm{G}>\mathrm{C}$ & 1 & $\mathrm{a}$ & & $\mathrm{x}$ & Germany \\
\hline & A195T & c. $583 \mathrm{G}>\mathrm{A}$ & 1 & $\mathrm{~h}$ & & & Austria \\
\hline & IVS6-1G>A & c. $636-1 \mathrm{G}>\mathrm{A}$ & 1 & $\mathrm{~h}$ & & $\mathrm{x}$ & Greece \\
\hline \multirow[t]{7}{*}{7} & P217L & c. $650 \mathrm{C}>\mathrm{T}$ & $2^{\star}$ & $\mathrm{a}$ & & $\mathrm{x}$ & Greece \\
\hline & R227P & c. $680 \mathrm{G}>\mathrm{C}$ & 3 & a & & & USA, England \\
\hline & F236L & c. $706 \mathrm{~T}>\mathrm{C}$ & 1 & $\mathrm{a}$ & & & Germany \\
\hline & P248L & c. $743 \mathrm{C}>\mathrm{T}$ & $6 \dagger$ & $\mathrm{a}$ & & $\mathrm{x}$ & Turkeyt, Italy \\
\hline & R257W & $\mathrm{v} 769 \mathrm{C}>\mathrm{T}$ & 1 & $\mathrm{c}$ & $\mathrm{x}$ & & Germany \\
\hline & S259P & c. $775 \mathrm{~T}>\mathrm{C}$ & 3 & $\mathrm{a}$ & & $\mathrm{x}$ & Germany \\
\hline & P278S & c. $832 \mathrm{C}>\mathrm{T}$ & 1 & $\mathrm{~h}$ & & & Germany \\
\hline \multirow[t]{3}{*}{8} & A293T & c. $877 \mathrm{G}>\mathrm{A}$ & $2^{\star}$ & $\mathrm{h}$ & $\mathrm{x}$ & & Chile \\
\hline & L309W & c. $926 \mathrm{~T}>\mathrm{G}$ & 1 & $\mathrm{~b}$ & & & England \\
\hline & R313Q & c. $938 \mathrm{G}>\mathrm{A}$ & 1 & $\mathrm{~b}$ & $\mathrm{x}$ & $\mathrm{x}$ & Germany \\
\hline 9 & $\mathrm{R} 355 \mathrm{H}$ & c. $1064 \mathrm{G}>\mathrm{A}$ & $3^{\star}$ & $\mathrm{h}$ & $\mathrm{x}$ & & Germany ${ }^{\star}$, Turkey \\
\hline \multirow[t]{7}{*}{10} & E365K & c. $1093 \mathrm{G}>\mathrm{A}$ & $5 \dagger$ & $\mathrm{a},(\mathrm{b})$ & $\mathrm{x}$ & & Turkeyt, USA \\
\hline & A $385 \mathrm{~V}$ & c. $1154 \mathrm{C}>\mathrm{T}$ & 1 & $\mathrm{~h}$ & & $\mathrm{x}$ & Chile \\
\hline & R386X & c. $1156 \mathrm{C}>\mathrm{T}$ & 1 & $\mathrm{~b}$ & $\mathrm{x}$ & & Germany \\
\hline & R402W & c. $1204 \mathrm{C}>\mathrm{T}$ & $24 \dagger$ & $\mathrm{h},(\mathrm{a})$ & $\mathrm{x}$ & & Germany, Europe \\
\hline & R402Q & c. $1205 \mathrm{G}>\mathrm{A}$ & $2^{\star}$ & $\mathrm{a}$ & $\mathrm{x}$ & & Germany \\
\hline & L407P & c. $1220 \mathrm{~T}>\mathrm{C}$ & $2^{\star}$ & $\mathrm{h}$ & & & Turkey \\
\hline & Y413X & c. $1239 \mathrm{C}>\mathrm{A}$ & 1 & $\mathrm{a}$ & & $\mathrm{x}$ & Greece \\
\hline \multirow[t]{2}{*}{11} & A421V (Amish) & c. $1262 \mathrm{C}>\mathrm{T}$ & $7^{\star}$ & $\mathrm{h}$ & & & Germany, Austria, Italy, Croatia \\
\hline & T429M & c. $1286 \mathrm{C}>\mathrm{T}$ & 1 & $\mathrm{a}$ & $\mathrm{x}$ & & Germany \\
\hline Total & 38 & & 96 & & 14 & 20 & \\
\hline
\end{tabular}

Haplotype $=$ haplotype as denoted in table $3 ; \mathrm{CpG}=$ hypermutable $\mathrm{CpG}$ mutation; Novel = novel mutation.

$\star=$ homozygous in one patient $t=$ homozygous in more than one patient; $\ddagger=$ apparent homozygosity in one patient that could also be the result of hemizygosity with a large deletion on the paternal chromosome. Haplotypes in parentheses were found on single chromosomes only. The numbering of cDNA nucleotides (c.) follows the recommendation of the Nomenclature Working Group ${ }^{9}$ and starts with 1 at the initiator codon; values are therefore 36 nucleotides smaller than those used in previous publications on GA1 mutations.

large number of Turkish patients with GA1. The commonest Turkish mutations with relative frequencies above $20 \%$ were P248L (5/18 alleles) and E365K (4/18 alleles). P248L was also identified in a compound heterozygous patient from Sicily, while the CpG mutation E365K was found in association with a different haplotype in a North American patient, again possibly reflecting independent recurrence. Differing haplotype associations were also found for one other $\mathrm{CpG}$ mutation, $\mathrm{R} 132 \mathrm{Q}$, in two patients of German and Turkish origin.

Table 3 Haplotypes in the GCDH gene

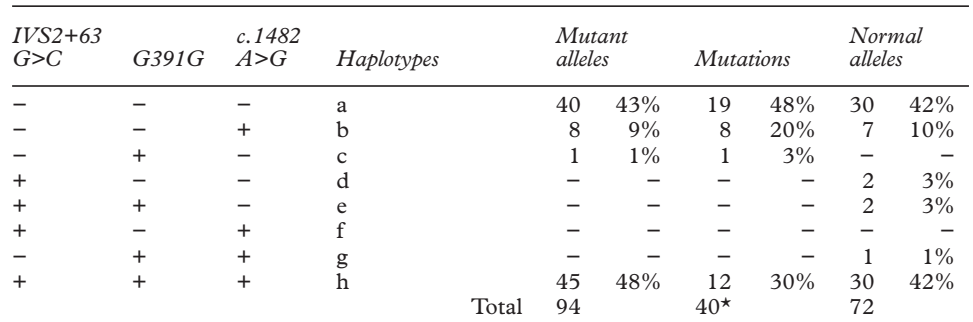

Haplotypes were determined from the analysis of three polymorphic markers, IVS $2+63 \mathrm{G}>\mathrm{C}$, G391G, and c. 1482A $>$ G, as indicated. Shown are total numbers and relative frequencies of haplotypes among mutant alleles, individual mutations, and normal alleles. ${ }^{\star}$ Three mutations were associated with two different haplotypes, while no haplotype could be assigned to one mutation, explaining the total of 40 .

\section{Discussion}

GA1 is very heterogeneous, and the pattern of mutations is typical for a disease that does not confer heterozygous advantage. Most mutations are private to individual patients, and the few more common mutations probably achieved their higher relative frequencies through recurrence, founder effect, and genetic drift. There is one relatively common mutation, R402W, that may be partly responsible for the relatively high incidence of GA1 in European populations. A large number of mutations involve hypermutable $\mathrm{CpG}$ sites in the gene, as would be expected for a disease in which a strong negative selection pressure (homozygosity for GA1 alleles is usually lethal if untreated) is counterbalanced by new mutations. The high proportion of homozygosity and consanguinity among GA1 families indicates that the frequency of mutant alleles (carrier status) in the general population is probably smaller than would be calculated using the Hardy Weinberg formula.

Previous reports have suggested that compound heterozygosity for mutation R227P and another mutation in the $G C D H$ gene is associated with lower urinary excretion of free glutarate, ${ }^{12}$ and this observation was confirmed in our study. All three patients who carried $\mathrm{R} 227 \mathrm{P}$ on one allele had atypical biochemical 
findings in urinary organic acid analysis (data not shown), and one of them had unusual isolated 3-hydroxyglutaric aciduria. ${ }^{13}$ This is most probably the result of significant residual enzyme activity, as has been shown recently by expression analysis of $\mathrm{R} 227 \mathrm{P}$ in $E$ coli. ${ }^{14}$ However, no strict correlation between biochemical and clinical phenotypes has yet been reported. It is interesting to note that all three patients with R227P were of Anglo-Saxon origin, and it is possible that this mutation may be more prevalent in this population.

Our results indicate that mutation analysis is a useful alternative for confirmation of diagnosis in patients with suspected GA1 when enzyme analysis is not available or feasible. We identified mutations on both alleles in all patients with enzymatically proven GDH deficiency including several patients with unusual biochemical features such as isolated excretion of 3-hydroxyglutaric acid or normal urinary organic acid profile. No mutation was found in patients in whom the diagnosis of GA1 was excluded through normal enzyme studies. Among these patients there were two with clinical features compatible with GA1 and consistent excretion of 3-hydroxyglutaric acid in the urine, a metabolite that has previously been regarded as pathognomonic for GDH deficiency. The underlying genetic defect in these children remains to be identified.

Broad range DGGE using a single, standard gel for all exons rapidly and reliably detected all heterozygous mutations in the present study and should be regarded as the method of choice for GA1 mutation analysis in a routine setting. Homozygous mutations that do not change the melting characteristics are not always recognised using this method, but this is easily circumvented by analysing at least one parent or mixing patient DNA with a normal control DNA sample. However, we did not encounter any mutations in exon 1 , which is very GC rich, nor exon 4, and we cannot therefore exclude the possibility that mutations in these exons or other mutations in other exons may be missed by our method. Furthermore, GA1 in some patients may be caused by large deletions or intron mutations that are not susceptible to simple PCR analysis. ${ }^{11}$

Direct measurement of GDH activity in fibroblasts or lymphocytes remains the diagnostic method of choice as it reflects the pathophysiology in the patient and provides information on residual enzyme activity. However, GDH assays are performed in only a few centres world wide and require the analysis of living cells which may not always be available. In contrast, small amounts of stored DNA or blood are sufficient for molecular analysis, and we have successfully used dried blood spots on old Guthrie cards for mutation detection by DGGE and sequencing. Our method also allows genetic testing in patient families and offers the possibility of reliable carrier analysis in unrelated spouses of GA1 patients. The clinical use of GA1 mutation analysis is restricted by a large number of private mutations of which the impact on GDH activity cannot be predicted. A degree of diagnostic uncertainty remains when novel mutations are found, particularly in patients who do not show the excretion pattern of urine metabolites typical of GA1. In these patients, mutation analysis alone is insufficent for confirmation of diagnosis, and enzyme analysis should also be performed. On the other hand, GDH deficiency in some patients may be caused by defects in the ETF binding site that would be missed by the enzymatic assay but detected by molecular analysis. No such defects have yet been described, but mutation analysis should be performed in all patients with clinical and biochemical diagnosis of GA1 but normal enzyme studies.

\section{Conclusion}

The DGGE method presented here may be used for the rapid and cost efficient molecular diagnosis of GA1, particularly when GDH enzyme analysis is not available or feasible. Comprehensive results in the family can be obtained within as little as one week, and the mutation information is particularly useful when prenatal diagnosis is considered for future pregnancies. It remains to be seen whether the wide range of genotypes observed in GA1 can be correlated to differences in residual enzyme activity, clinical features, and outcome.

We wish to thank patients, parents, and the referring clinicians for providing blood samples. The study was supported by the Deutsche Forschungsgemeinschaft (Zs 17/3-1).

1 Hoffmann GF, Athanassopoulos A, Burlina A, et al. Clinical course, early diagnosis, treatment and prevention of disease in glutaryl-CoA dehydrogenase deficiency. Neuropediatrics 1996;27:115-23.

2 Baric I, Zschocke J, Christensen E, et al. Diagnosis and management of glutaric aciduria type I. F Inherit Metab Dis 1998;21:326-40.

3 Goodman SI, Kratz LE, DiGiulio KA, et al. Cloning of glutaryl-CoA dehydrogenase cDNA, and expression of wild type and mutant enzymes in Escherichia coli. Hum Mol Genet 1995;4:1493-8.

4 Schwartz M, Christensen E, Superti-Furga A, Brandt NJ. The human glutaryl-CoA dehydrogenase gene: report of intronic sequences and of 13 novel mutations causing glutaric aciduria type I. Hum Genet 1998;102:452-8.

5 Goodman SI, Stein DE, Schlesinger S, et al. Glutaryl-CoA dehydrogenase mutations in glutaric acidemia (type I): review and report of thirty novel mutations. Hum Mutat 1998;12:141-4

6 Biery BJ, Stein DE, Morton DH, Goodman SI. Gene structure and mutations of glutaryl-coenzyme A dehydrogenase: impaired association of enzyme subunits that is due to an A421V substitution causes glutaric acidemia type I in the Amish. Am ₹ Hum Genet 1996;59:1006-11.

7 Guldberg P, Güttler F. 'Broad-range' DGGE for single-step mutation scanning of entire genes: application to human phenylalanine hydroxylase gene. Nucleic Acids Res 1994;22: $880-1$.

8 Eiken HG, Odland E, Borman H, Skjelkvåle L, Engebretsen LF, Apold J. Application of natural and amplification created restriction sites for the diagnosis of PKU mutations. Nucleic Acids Res 1991;19:1427-30.

9 Antonarakis SE, the Nomenclature Working Group. RecAntonarakis SE, the Nomenclature Working Group. Rec-
ommendations for a nomenclature system for human gene mutations. Hum Mutat 1998;11:1-3.

10 Bird AP. CpG-rich islands and the function of DNA methylation. Nature 1986;321:209-13

11 Zschocke J, Quak E, Knauer A, Fritz B, Aslan M, Hoffman GF. Large heterozygous deletion masquerading as homozygous missense mutation: a pitfall in diagnostic mutation analysis. F Inherit Metab Dis 1999;22:687-92.

12 Christensen E, Ribes A, Busquets C, et al. Compound heterozygosity in the glutaryl-CoA dehydrogenase gene with R227P mutation in one allele is associated with no or very low free glutarate excretion. F Inherit Metab Dis 1997;20: 383-6.

13 Nyhan WL, Zschocke J, Hoffmann GF, Stein DE, Bao L, Goodman S. Glutaryl-CoA dehydrogenase deficiency presenting as 3-hydroxyglutaric aciduria. Mol Genet Metab 1999;66:199-204.

14 Liesert M, Zschocke J, Hoffmann GF, Mühlhäuser N, Buckel W. Biochemistry of glutaric aciduria type I: activities of in vitro expressed wild-type and mutant cDNA encoding human glutaryl-CoA dehydrogenase. $\mathcal{F}$ Inherit Metab Dis 1999;22:256-8. 